\title{
TRAÇO: PULSO PRIMORDIAL IMAGENS EM MOVIMENTO ENTRE CAVERNAS E GALERIAS
}

\author{
Ana Elisa de Castro Freitas ${ }^{1}$ \\ Antônio Augusto Bueno ${ }^{2}$ \\ Jaciele Nyg Kuitá Fidelis ${ }^{3}$
}

\section{Linhas e pontos sem amarração}

Entre janeiro e fevereiro de 2016 percorri as escarpas devonianas dos Campos Gerais do Paraná, na bacia hidrográfica do Rio Tibagi. Suas águas, campos e florestas acolhem há milhares de anos o olhar e o gesto. As superfícies e tonalidades das formas se diluem nas matérias telúricas; os espaços afetam o olhar. A paisagem soa familiar à vida humana. As escarpas dos Campos Gerais são território imemorial de ocupação ameríndia, há mais de 11 mil anos. O horizonte dos campos é entremeado por capões de Mata com Araucária (Floresta Ombrófila Mista), sobressaindo entre as copas das árvores mais altas as ramagens do pinheiro brasileiro.

A floresta avança pelos sulcos dos vales profundos, recobrindo os afloramentos rochosos. Nas encostas dos vales, inúmeros refúgios de pedra convidam ao repouso nos dias quentes, ou ao abrigo nos tempos invernais. Essa fabulosa paisagem cultural se estende pelos municípios de Piraí do Sul, Ponta Grossa, Castro, Tibagi, Sengés, entre outros da região nordeste do Paraná.

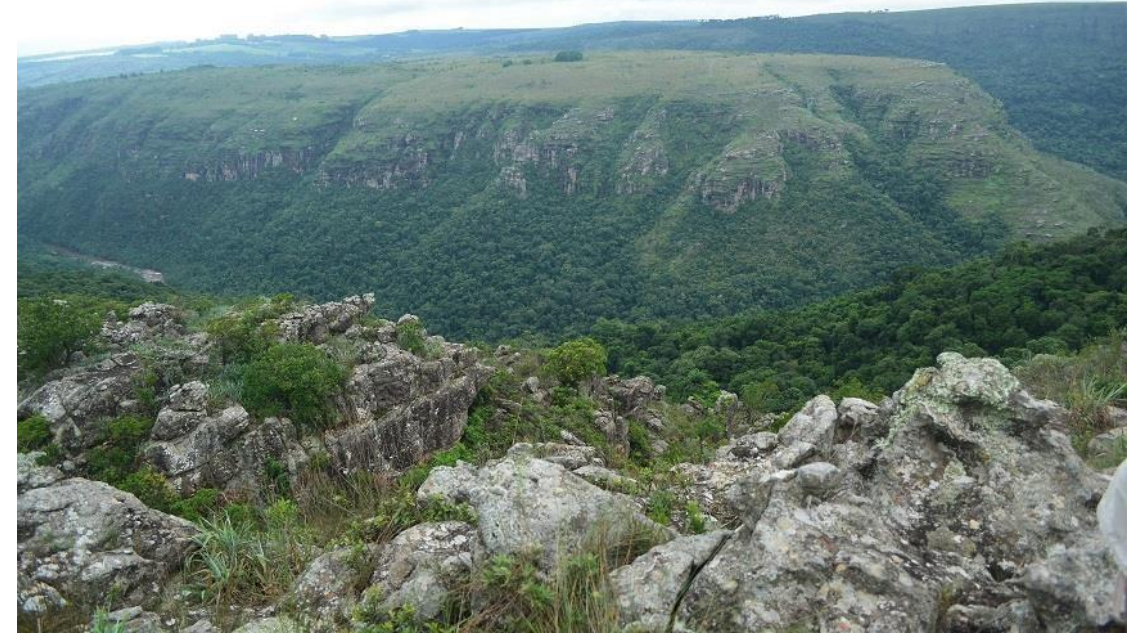

Figura 1 - Escarpas do cânion Guartelá, Campos Gerais, Tibagi, Paraná. Foto da autora.

\footnotetext{
${ }^{1}$ Atelier Planta Baja; Universidade Federal do Paraná, Brasil.

${ }^{2}$ Atelier Jabutipê, Porto Alegre, Brasil.

${ }^{3}$ Terra Indígena Apucaraninha; Universidade Federal do Paraná, Brasil.
} 
No interior dos abrigos de pedra, traços figurativos e abstratos demarcam as paredes rochosas. De coloração vermelha escura, laranja e ocre, inscritos há milhares de anos, os desenhos rupestres dos Campos Gerais incluem um vasto repertório de pontos, traços livres e formas variadas, sendo relacionados às oficinas líticas das tradições arqueológicas préceramistas Umbu (300-11.500 anos A.P.) e/ou Humaitá (1.130-8.700 A.P.) (Gomes, 2011). Em continuidade a essas ocupações humanas primordiais, os Campos Gerais recepcionaram fluxos ameríndios vinculados aos vestígios de tradições arqueológicas ceramistas Itararé e Casa de Pedra; acolheram vias migratórias Jê Meridional, a partir do Planalto Central, e definem até os dias de hoje o centro do território Kaingang no Planalto Sul Brasileiro (Tomasino, 1995; Noelli e Souza, 2017).
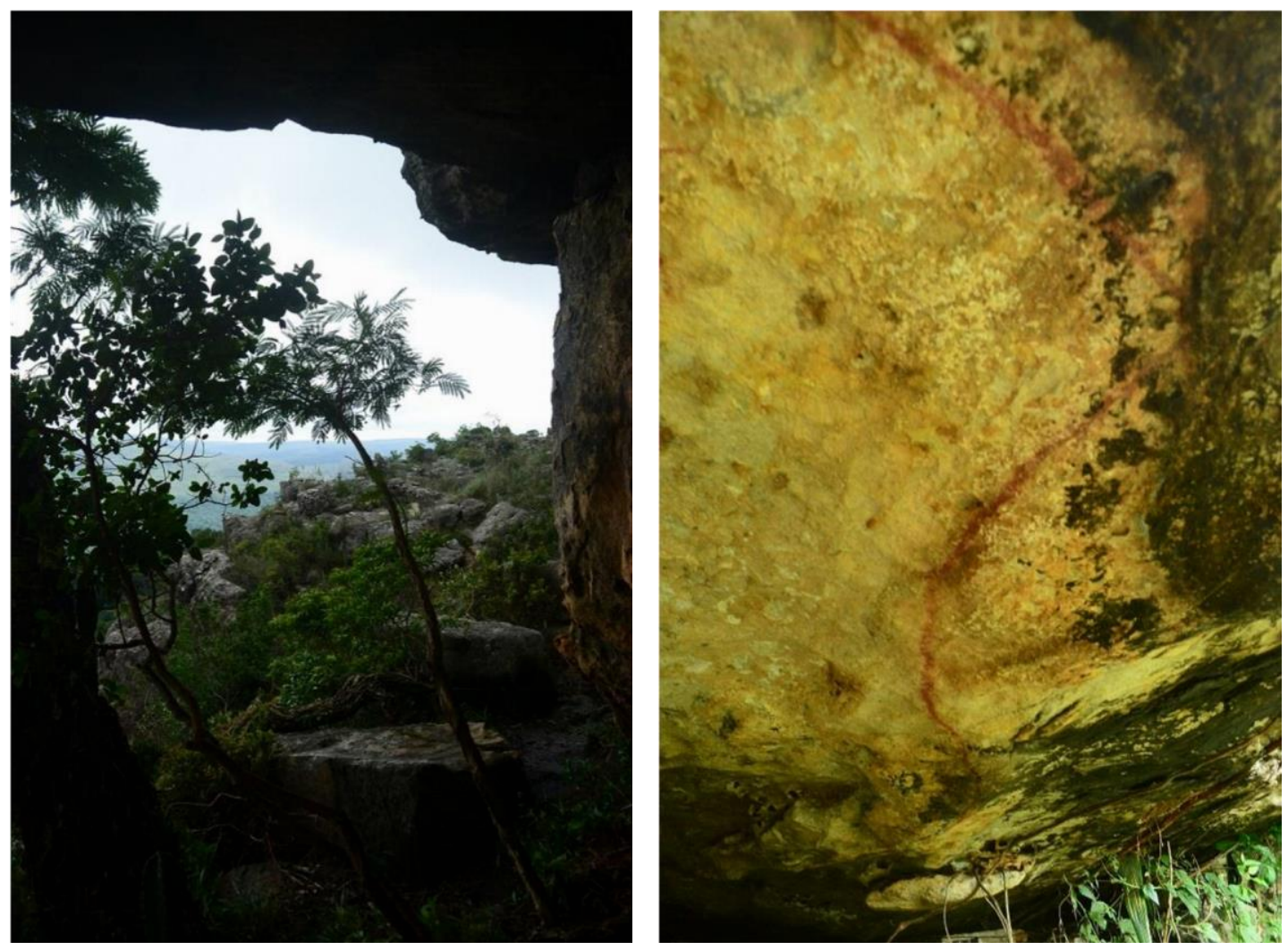

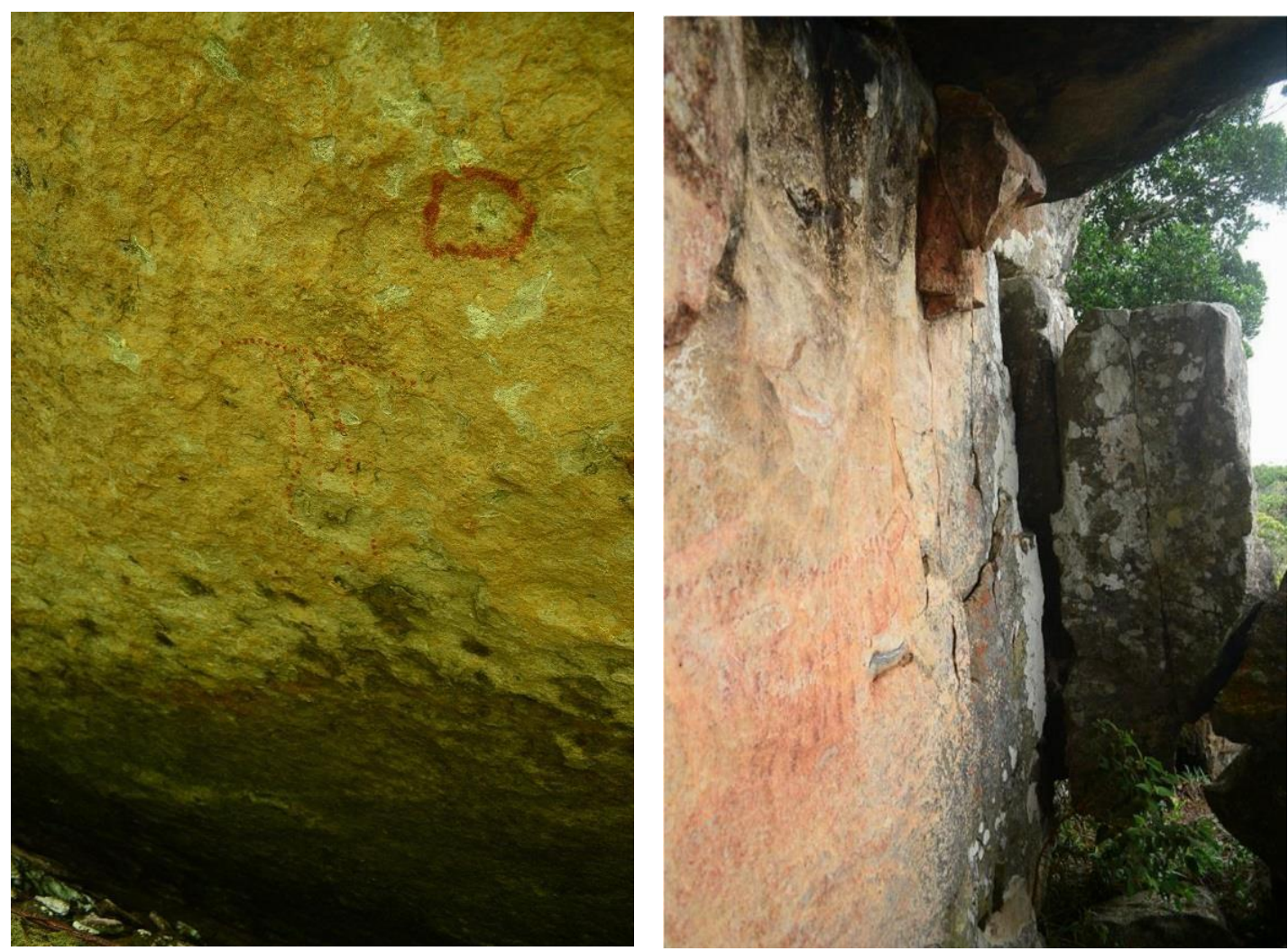

Figura 2 - Sequência de imagens de um abrigo rochoso com pinturas rupestres. Escarpas do cânion Guartelá, Trilha da Camboa, Campos Gerais, Tibagi, Paraná. Fotos da autora.

A pesquisadora Cinara de Souza Gomes (2011: 18) recupera os primeiros registros coloniais sobre os desenhos inscritos nas pedras de Piraí do Sul, destacando um artigo assinado por João Gnoato e publicado em 17 de fevereiro de 1956 no jornal "O Dia" de Curitiba, exatamente 60 anos antes da minha expedição aos Campos Gerais.

De acordo com Cinara Gomes (2011: 18), a notícia jornalística dos desenhos mobilizou, no mesmo ano, uma expedição liderada por Oldemar Blasi, vinculado ao Instituto de Pesquisas do Paraná e à Universidade Federal do Paraná, acompanhado pelos arqueólogos franceses Annete Laming e Joseph Emperair. De meados da década de 1950 até o presente as inscrições rupestres dos Campos Gerais recepcionam expedições científicas similares àquela, dedicadas ao registro e inventário do patrimônio cultural, artístico e arqueológico a elas relacionado.

Sem desconhecer a relevância desses estudos, minha viagem estava motivada por outras intimações. Inicialmente, buscava dar continuidade a estudos etnográficos que focalizam a arte indígena tomando em consideração conceitos, seres e matérias mobilizados pelos pensamentos ameríndios. Tais estudos priorizam a interpretação dos processos criativos 
considerando a posição e os deslocamentos empreendidos pelos sujeitos criadores na teia de relações que estabelecem em seus ambientes de vida. A perspectiva desses estudos tem envolvido a imersão etnográfica nas paisagens conceituais do jykre/pensamento Kaingang (Freitas, 2005; 2014; Freitas e Jacinto da Rosa, no prelo), convergindo para as interfaces da antropologia da imagem com a antropologia ecológica (Ingold, 2015), e fertilizando outros campos pela atuação criativa de intelectuais indígenas que participam das pesquisas e seguem por novos caminhos (e.g. Jacinto da Rosa, 2015; Vergueiro, Mello e Pires, 2015; Pires, 2017; Silva, 2017).

As motivações da viagem também envolviam pesquisas iniciais que elegem a criação iconopoética como via de registro e expressão sensível dos diálogos interculturais (Freitas, 2018). Entendo o ensaio iconopoético como uma modalidade textual que enseja a produção intelectual por meio de criações estéticas, potencializando a mobilização dialética de imagens. Tenho investido na pesquisa de estratégias narrativas iconopoéticas na intenção de nutrir a escrita com elementos da arte e deliberadamente borrar horizontes culturais e disciplinares, imaginando poros que possibilitem fluidez entre as etnologias indígenas, a arte contemporânea, a filosofia, a antropologia, a ecologia, em constelações sempre abertas, tendo por inspiração as ideias de imagem em movimento, de Aby Warburg (2015), e de imagem dialética, de Walter Benjamin (1995; 2012).

A expedição aos Campos Gerais buscava reconhecer elementos materiais e imateriais capazes de potencializar as rotas criativas e os fluxos dialógicos com os pensamentos ameríndios, avançar nas produções compartilhadas com intelectuais indígenas (Freitas e Rokàg dos Santos, 2008; Freitas e Harder, 2018; Freitas e Jacinto da Rosa, no prelo), assumindo a tarefa da tradução, no sentido que lhe confere Walter Benjamin (2011).

E para além de toda tarefa, o desejo era ativar as forças imaginantes (Bachelard, 1989; 1990; 1991). Queria que as imagens rupestres indicassem um caminho às pulsões gráficas primordiais, ativando a imaginação das forças, motivadora da criação artística. Para tanto, foi necessário deslocar a forma das amarras da duração, rever as imagens gráficas rupestres experimentando a perspectiva do olhar no instante do gesto, de modo a liberar o traço e revisitar o instante vibrante do processo criador.

Tal movimento é aderente à rítmica circular do tempo e da perspectiva histórica não linear vigente no jykre/pensamento Kaingang, em que o Uri/presente é imagem dialética do próprio Waxi/passado, e vice-versa (Freitas, 2014; Jacinto da Rosa, 2015). 
Nas trilhas do cânion Guartelá, desejava ser tomada de improviso e deslocar as pinturas rupestres das amarras disciplinares, das escalas do tempo linear e da continuidade histórica; aproximar o traço de seu pulso primordial e tocar o Uri/tempo presente Kaingang com imagens potentes do Gufã/tempo imemorial dos primórdios ancestrais; vencer o frio da ciência para aquecer a imaginação criativa que move a mão, encanta a matéria, evoca e imprime o traço.

Labaredas de imagens verteram pelas paredes de pedra. Esboços e notas foram registrados no caderno de campo simultaneamente à experiência, tal como sugere Paul Klee em seus notebooks $(1961 ; 1973)$.

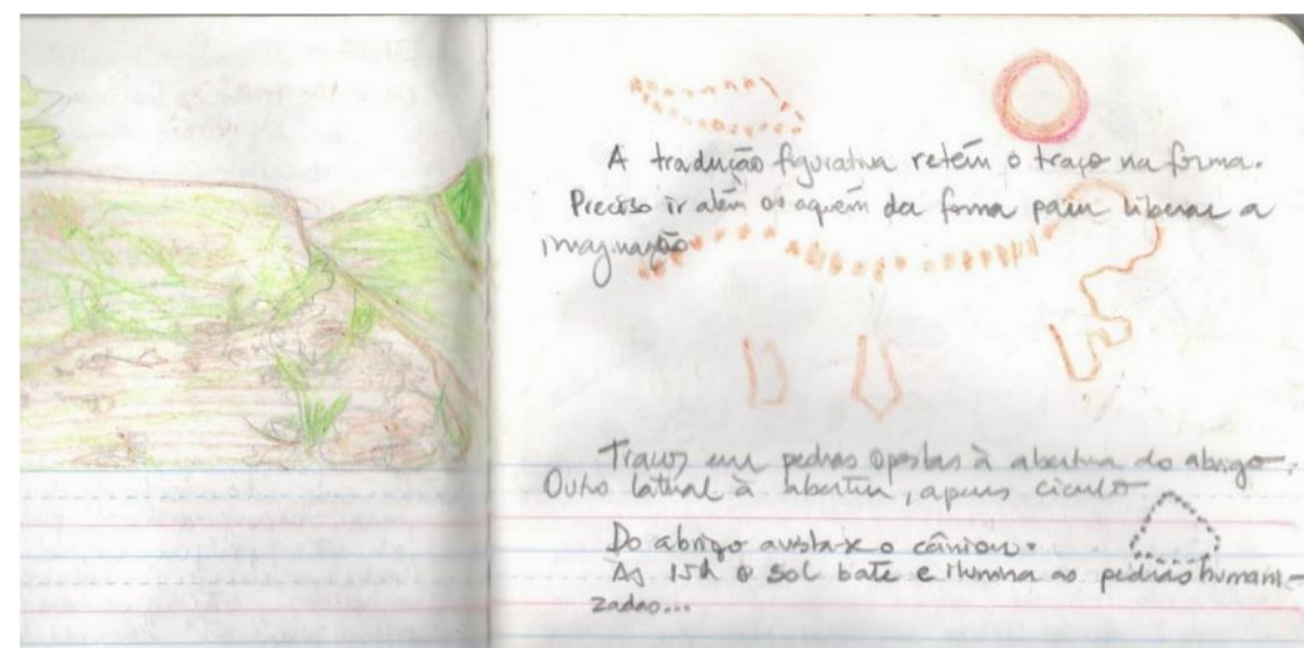

Figura 3 - Fragmento de notebook.

Os sítios arqueológicos de outrora se configuravam agora como ateliês de arte, e os desenhos rupestres alçavam o espaço como imagens dialéticas, num devir contemporâneo. Procedi fotografias e notas de campo das pinturas rupestres, das paisagens visíveis e audíveis desde o interior dos abrigos rochosos e das imagens evocadas durante a observação, constituindo um primeiro conjunto de registros de pesquisa. $\mathrm{O}$ processo de imersão nas galerias de arte ameríndia desdobrou-se em inúmeros percursos etnográficos pelos caminhos do território. Matérias da terra foram ativadas, mobilizadas e deslocadas. Pequenas pedras e sedimentos telúricos de diferentes tonalidades, ricos em óxidos ferrosos e manganês, foram coletados e cuidadosamente dispostos em frascos e potes, ativando as vias de imaginação da matéria (Bachelard, 1989). 


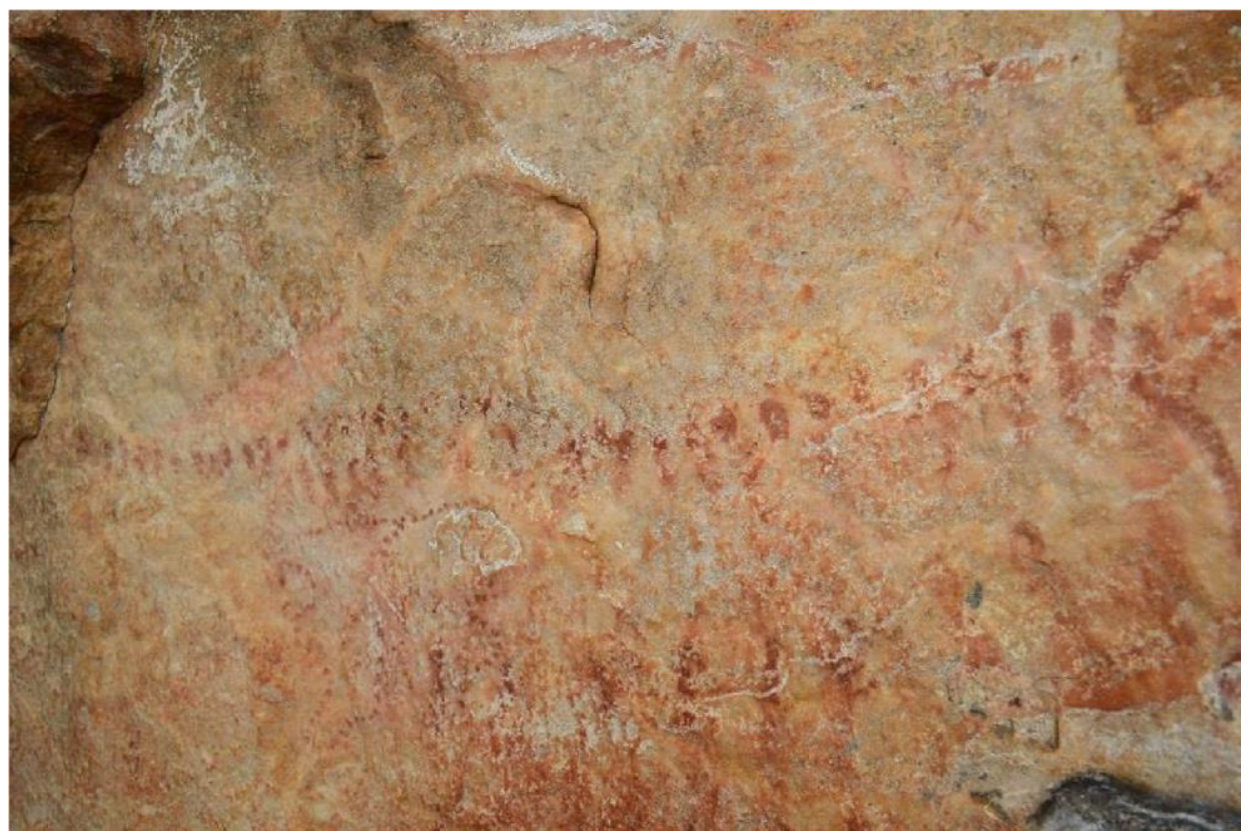

Figura 4 - Desenho em abrigo de pedra, cânion do Guartelá, Paraná. Foto da autora.

De volta ao Laboratório de Interculturalidade e Diversidade/LaID, no Setor Litoral da Universidade Federal do Paraná, entre março e abril de 2016 as fotografias, notas de campo e matérias da terra foram catalogadas, ampliadas, dispostas em suportes acrílicos que possibilitassem sua visibilidade. Chamava a atenção o caráter contemporâneo latente naquelas imagens, outrora restritas ao campo dos achados arqueológicos. Ativadas pela imaginação da matéria e das forças imaginantes as imagens das pinturas rupestres improvisaram outros deslocamentos.

Ainda no mês de abril empreendi viagem a Porto Alegre, iniciando um diálogo potente com o artista plástico Antônio Augusto Bueno. Na mala de viagem seguiram comigo fotografias dos traços rupestres, matérias telúricas e notas de campo. Cheguei no Atelier Jabutipê, localizado no centro histórico da cidade de Porto Alegre - um casarão situado à rua do Arvoredo/Fernando Machado, número 195.

$\mathrm{Na}$ mesa de entrada dispus as imagens das inscrições rupestres ameríndias, as notas de campo e matérias telúricas. Como num clarão, os traços ancestrais estabeleceram conexões inusitadas com gravuras de arte contemporânea produzidas em séries por Antônio Augusto Bueno. 


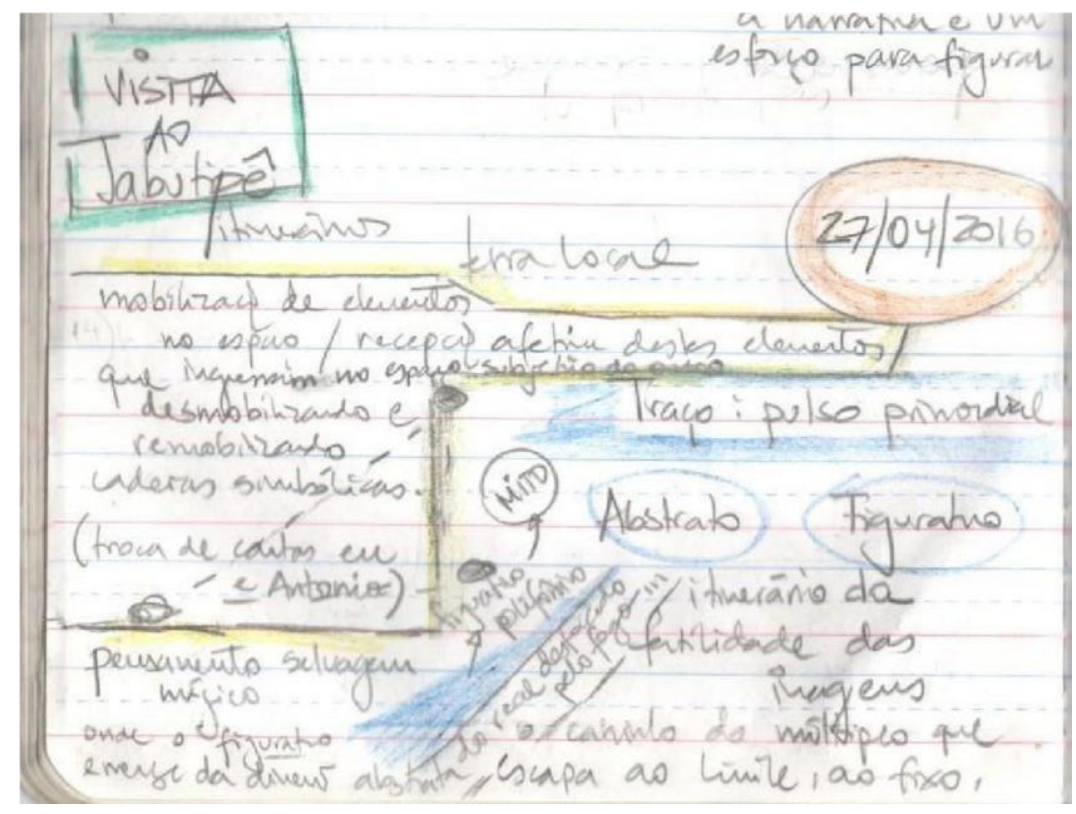

Figura 5 - Fragmento de notebook, abril de 2016.

Constelações heteróclitas e atemporais foram-se configurando e desconfigurando, em arranjos moveis. Fomos tomados pela potência das imagens dialéticas que do Outrora desalojavam o Agora, desacomodando as rotas de criação artística.

Impressionava a contemporaneidade assumida pelas pinturas rupestres, desde o instante em que ingressaram no atelier de arte. Instigados pela potência do instante, fomos tomados pelo devir dialético das imagens, seguindo seu fluxo - e nele reconhecemos o conceito para uma exposição de arte contemporânea. 

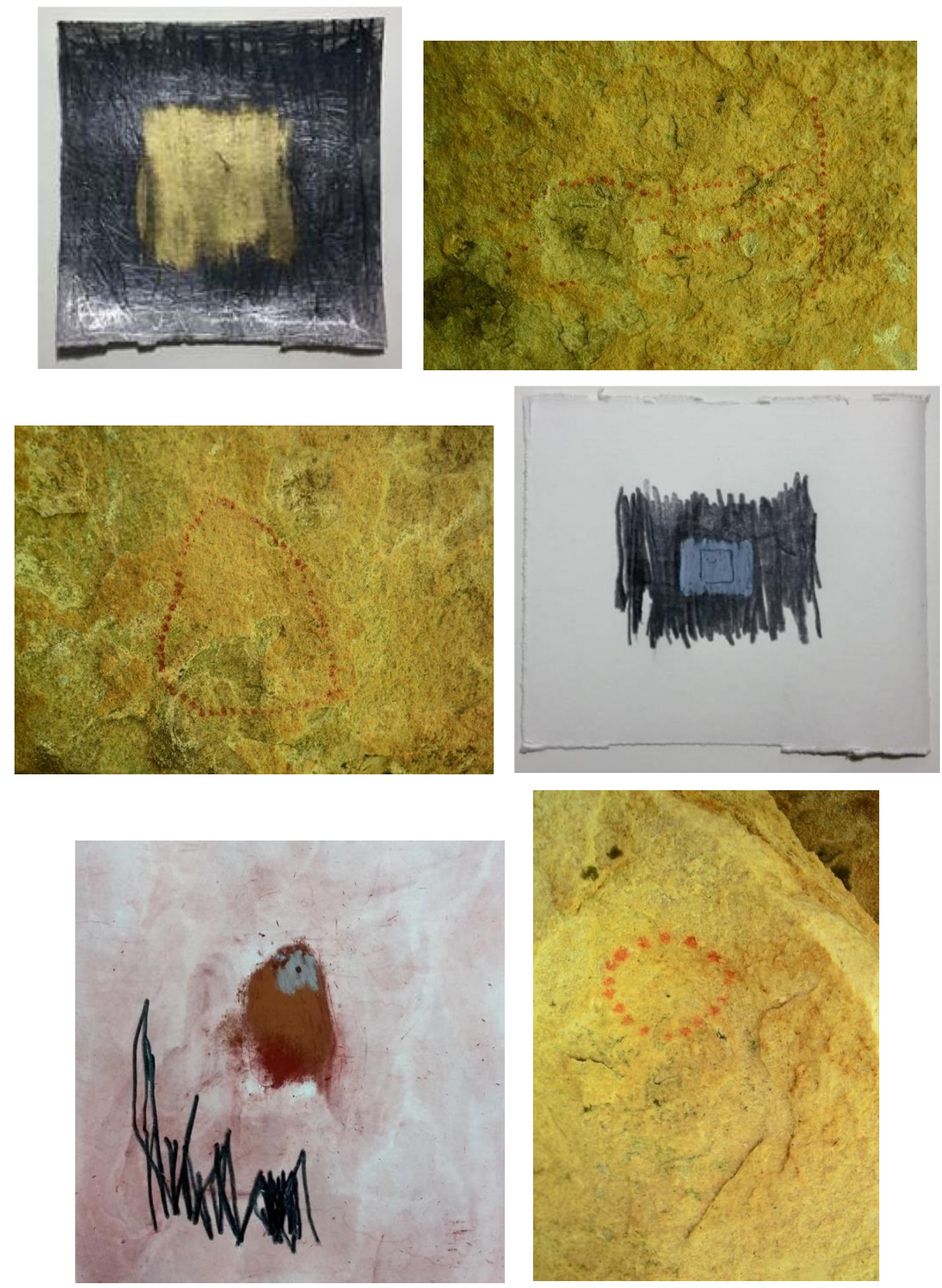

Figura 6 - Constelação de desenhos rupestres e gravuras contemporâneas, de autoria do artista plástico Antônio Augusto Bueno. Fotos das pinturas rupestres da autora; fotos das gravuras por Antônio Augusto Bueno.

De volta ao Atelier Planta Baja, em Matinhos, litoral do Paraná, escrevi uma proposta inicial de montagem para a instalação artística, integrando fotografias, gravuras e matérias da terra. Submeti a proposta "Traço: pulso primordial” a processo seletivo, estabelecido em edital pelo espaço de arte Grafatório, localizado na cidade de Londrina, norte do Paraná. 
A proposta foi selecionada para integrar uma exposição coletiva de arte contemporânea intitulada "Líquido que nem Pedra", com inauguração prevista para novembro de 2016, no Grafatório, Londrina.

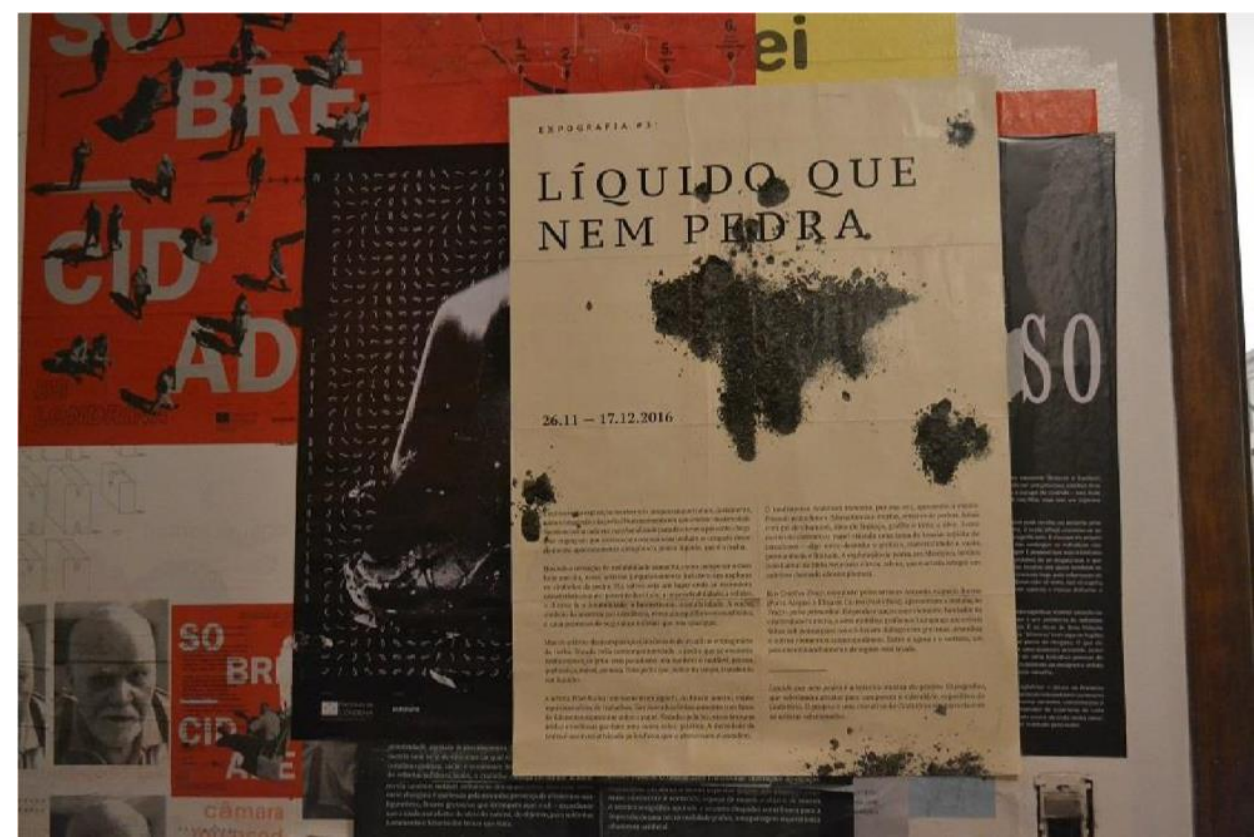

Figura 7 - Cartaz da exposição coletiva de arte contemporânea "Líquido que nem Pedra", nas paredes do Grafatório, na cidade de Londrina, Paraná.

Na primeira semana de novembro, Antônio Augusto Bueno se deslocou de Porto Alegre a Matinhos, permanecendo alguns dias em residência artística no Atelier Planta Baja. Intensificamos os estudos experimentais acerca do potencial plástico das terras vermelhas da bacia hidrográfica do Tibagi, em diferentes suportes, incluindo as paredes do atelier.

Ensaiamos linhas de montagem para as fotografias e gravuras.
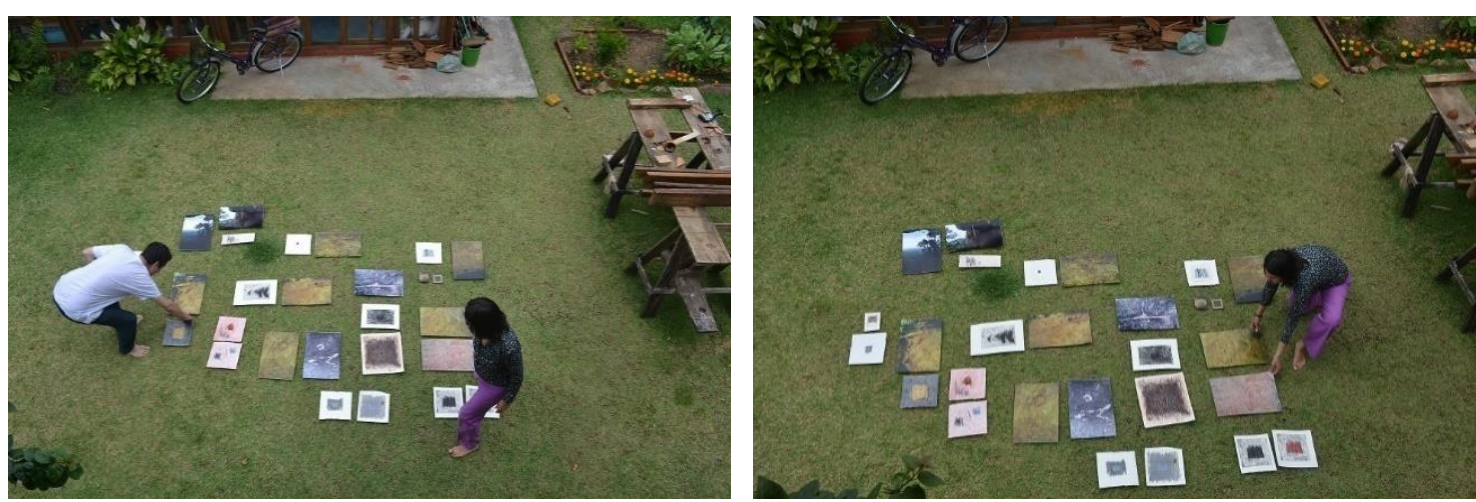

Figura 8 - Ensaios experimentais de linhas de montagem no Atelier Planta Baja, Matinhos, Paraná. Fotos de João Francisco Freitas Scherer. 
Nessa etapa do processo criativo intensifiquei o diálogo com intelectuais indígenas que colaboram como pesquisadores associados no Laboratório de Interculturalidade e Diversidade, especialmente Jaciele Nyg Kuitá Fidelis, acadêmica do curso de Serviço Social no Setor Litoral da Universidade Federal do Paraná, jovem Kaingang pertencente ao território ancestral dos Campos Gerais, Terra Indígena Apucaraninha, bacia hidrográfica do Rio Tibagi. A imediata conexão das forças imaginantes de Nyg com as fotografias das pinturas rupestres abriu outros caminhos para a montagem da exposição, que desde então contou com sua intensa participação. Juntos, cedemos à força e ao fluxo das intimações do Gufã/tempo imemorial, fertilizando o Uri/tempo presente com a potência criativa dos traços primordiais. Dialeticamente, o presente despertava o passado de um sono profundo.

A ideia da montagem incluiu a livre criação e inscrição de traços inspirados nos grafismos rupestres primordiais nas paredes do espaço expositivo do Grafatório, em Londrina, utilizando tinturas elaboradas a partir da diluição de terra em água, e previamente experimentadas no Atelier Planta Baja. As matérias do território se tornaram elas mesmas fontes de ativação imaginária na direção do traço - pulso primordial do ato criativo, acidente atemporal, célula-síntese de imaginários plurais em movimento.

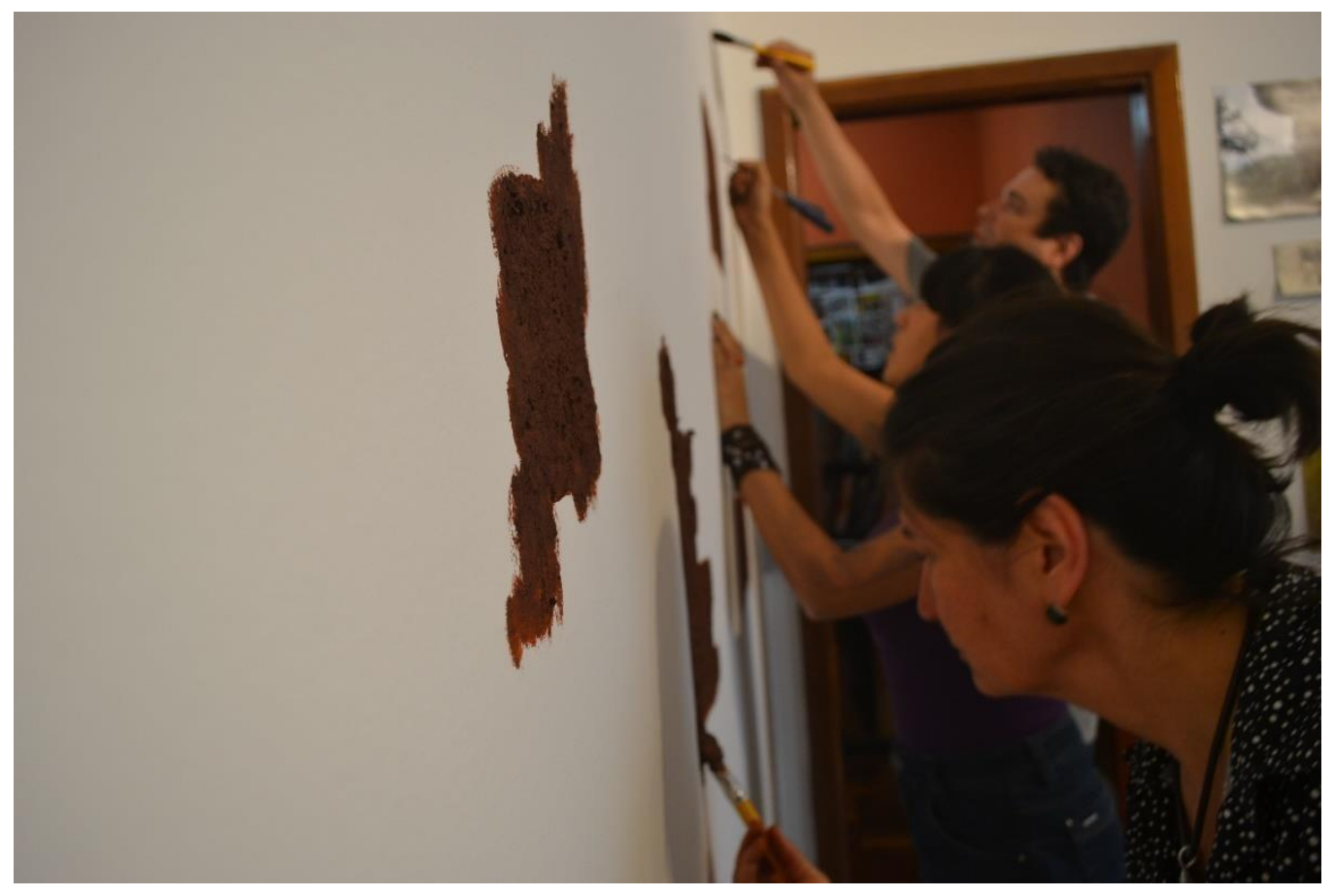




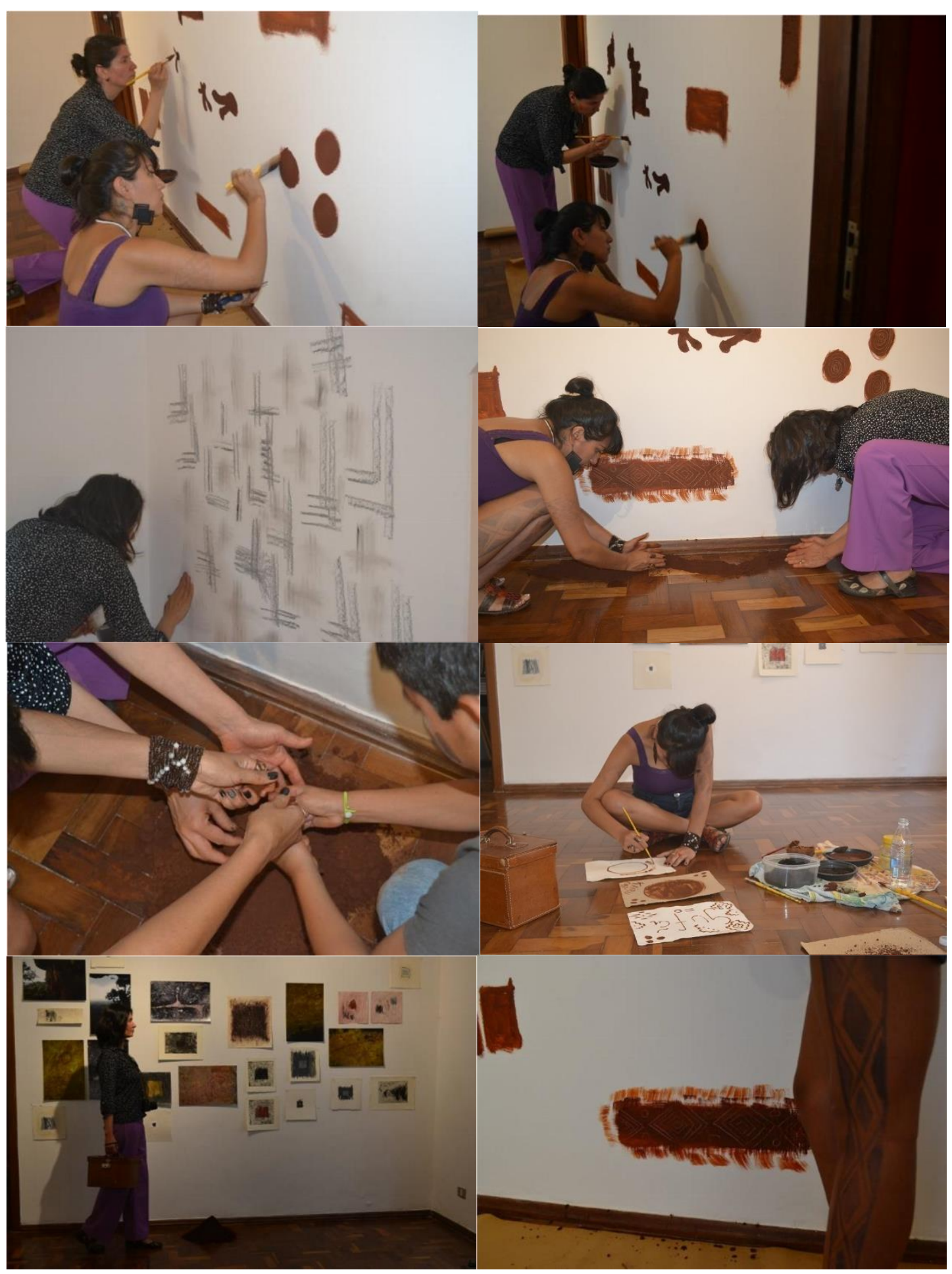




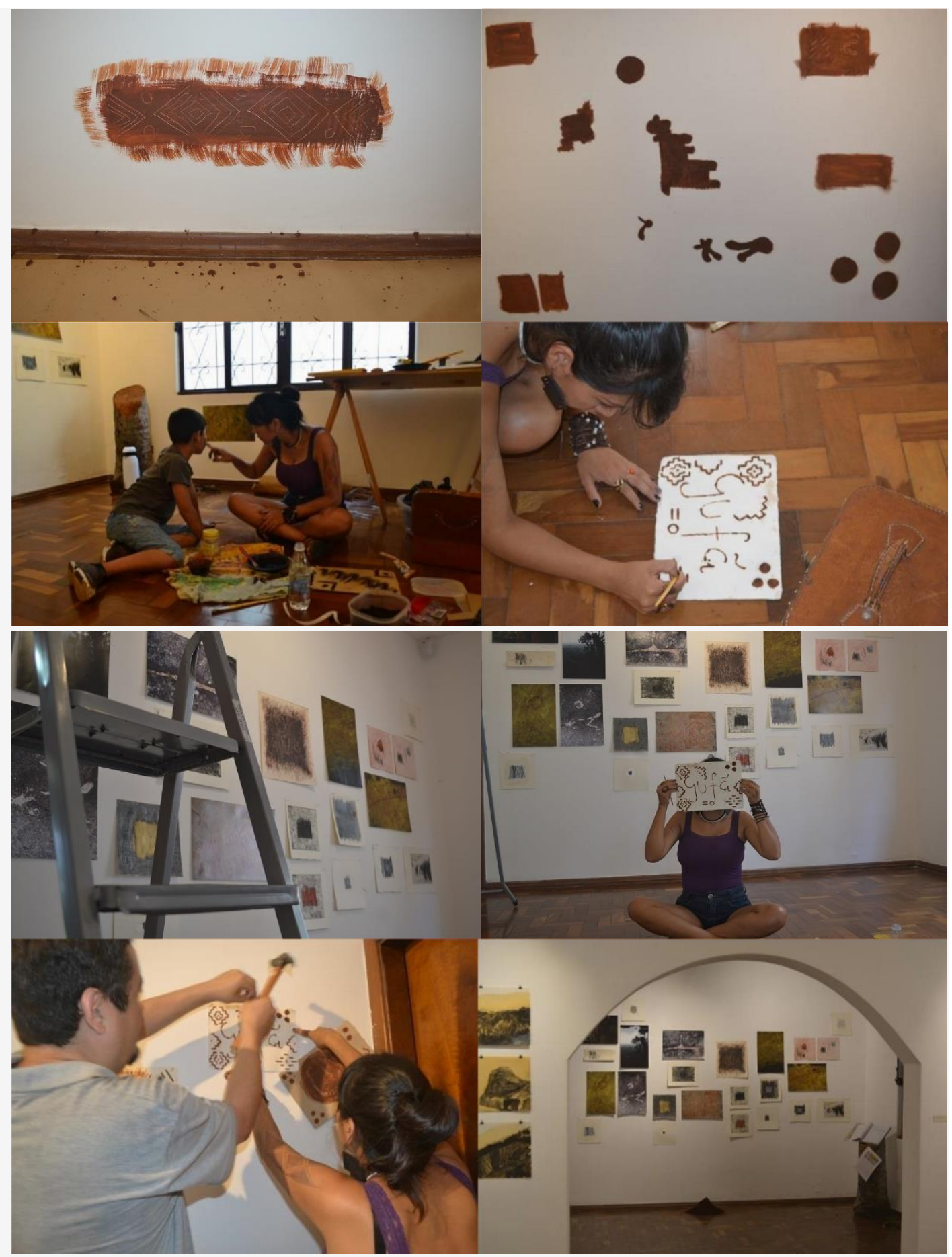

Iluminuras, Porto Alegre, v. 19, n. 46, p. 436-450, jan/jul, 2018. 


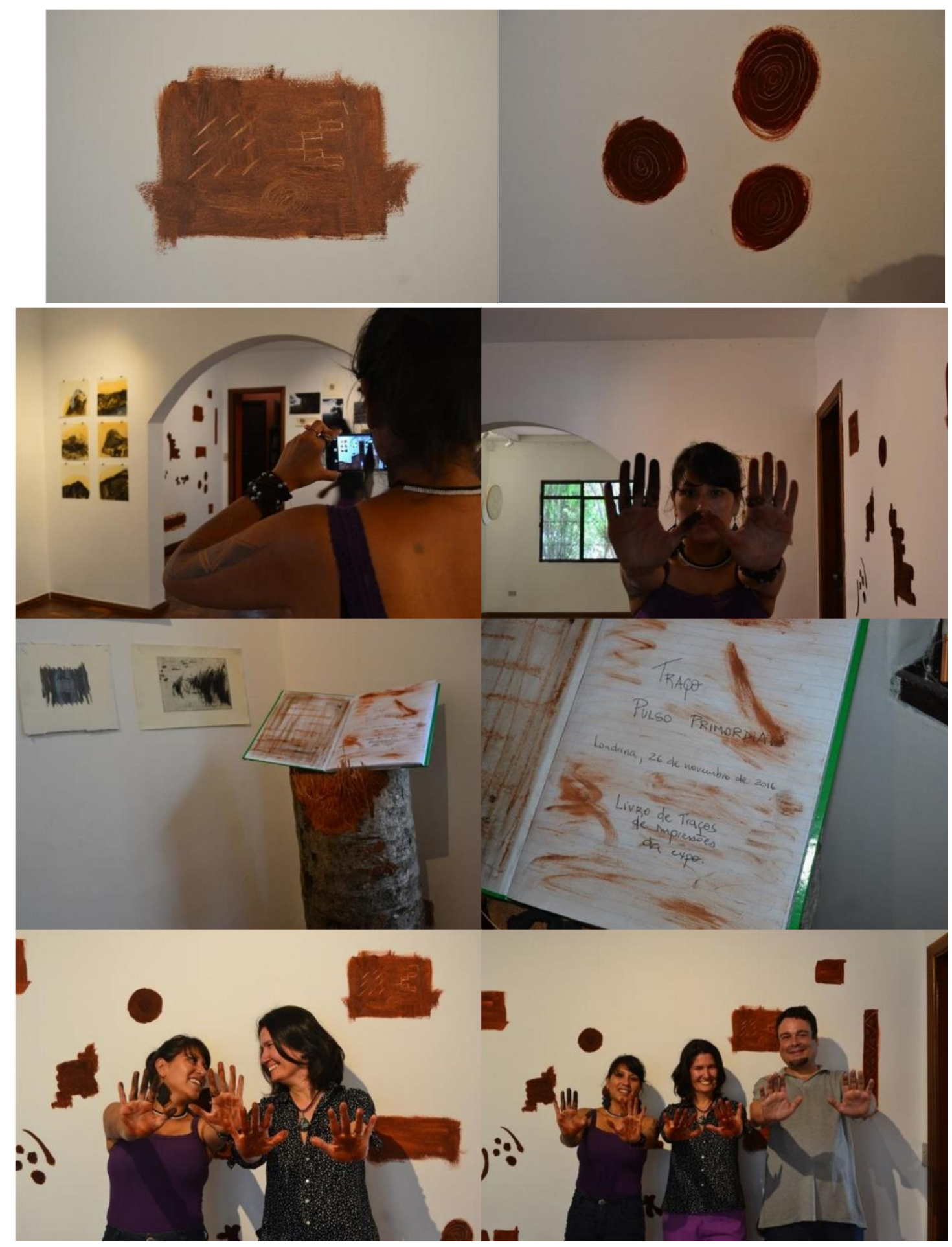

Figura 9 - Sequências de narrativa visual registrando os autores durante a montagem da exposição "Traço: pulso primordial", na coletiva de arte contemporânea "Líquido que nem Pedra", espaço de arte Grafatório, Londrina, Paraná. Novembro de 2016. Fotos de Tatiana Ramos. 


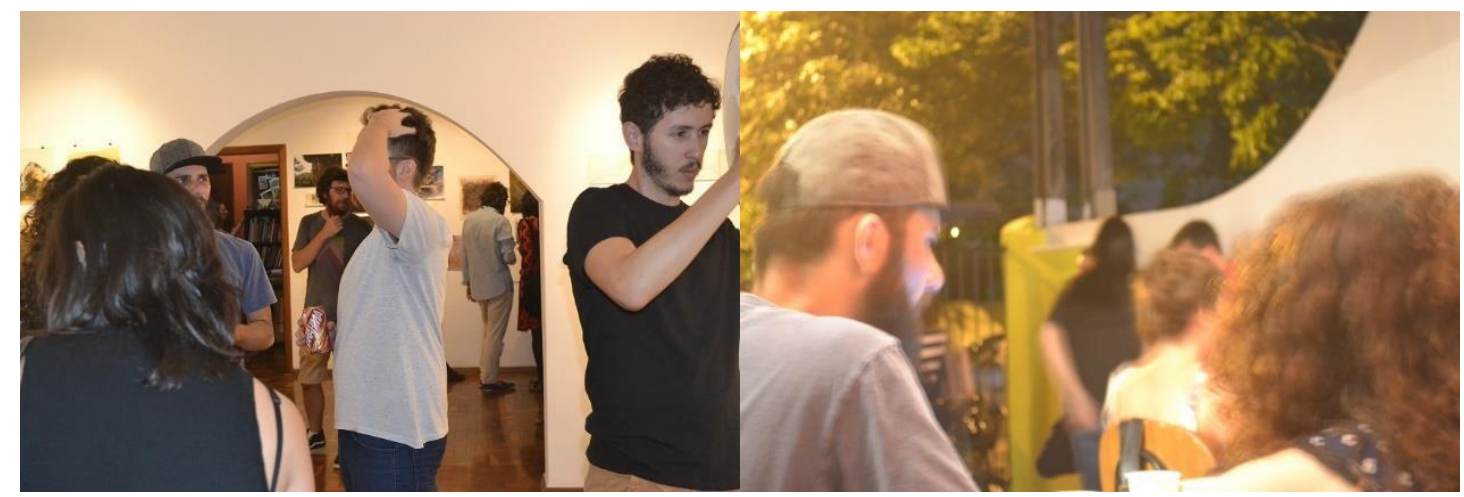

Figura 10 - Registros da vernissage da exposição coletiva de arte contemporânea "Líquido que nem

Pedra", no espaço de arte Grafatório, Londrina, Paraná. Novembro de 2016. Fotos de Tatiana Ramos.

Agradecimentos: Agradecemos a Eduardo Harder, João Francisco Freitas Scherer, Carolina Freitas Scherer, Tatiana Ramos e Rogério Bernardi pelo dedicado suporte na etapa de montagem da exposição, registro fotográfico e hospedagem em Londrina. Aos artistas do Grafatório, especialmente ao Edson Vieira.

\section{Referências Bibliográficas:}

BACHELARD, Gaston. A Água e os Sonhos: ensaio sobre a imaginação da matéria. São Paulo: Martins Fontes, 1989. . A Terra e os Devaneios do Repouso: ensaio sobre as imagens da intimidade. São Paulo: Martins Fontes, 1990.

A Terra e os Devaneios da Vontade: ensaio sobre imaginação das forças. São Paulo: Martins Fontes, 1991.

BENJAMIN, Walter. Obras Escolhidas II - Rua de Mão Única. 5a. Ed. São Paulo: Brasiliense, 1995.

A tarefa do tradutor. In: BENJAMIN, Walter. Escritos sobre mito e linguagem. Coleção Espírito Crítico. São Paulo: Ed. Duas Cidades; Ed. 34, 2011, pp. 101-119.

. Magia e Técnica, Arte e Política: ensaios sobre literatura e história da cultura. Obras escolhidas - Vol.I. $8^{\text {a }}$ Ed. São Paulo: Brasiliense, 2012.

FOUCAULT, Michel. Isto não é um cachimbo. Rio de Janeiro: Paz e Terra, 2008.

FREITAS, Ana Elisa de Castro; ROKÁG DOS SANTOS, Francisco. O kujà e o sistema de medicina tradicional kaingang: "por uma política do respeito": Relatório do II Encontro dos Kujà, Terra Indígena Kaingang Morro do Osso, Porto Alegre, Rio Grande do Sul, Brasil. Cadernos do LEPAARQ, Pelotas, v. 4, n. 7/8, p. 201-239, 2007.

FREITAS, Ana Elisa de Castro; BUENO, Antônio Augusto e KUITÁ FIDELIS, Jaciele Nyg. Traço: Pulso Primordial. Exposição de Arte Contemporânea. Londrina: Grafatório, 2016.

FREITAS, Ana Elisa de Castro. Garra de jaguar, botão de camisa, cartucho de bala: um olhar sobre arte, poder, prestígio e xamanismo na cultura material Kaingang. MEDIAÇÕES, 
Londrina, V. 19 N. 2, P. 62-83, Dossiê - estudos sobre as sociedades Jê (Kaingang e Xokleng) no Sul do Brasil. JUL./DEZ. 2014.

Nas brumas revigorantes de Jakaira Chy Ete, o encantamento feminino das belas palavras Mbya Guarani. Das Questões, n.5, janeiro/julho, 2018.

FREITAS, Ana Elisa de Castro e HARDER, Eduardo. O ofício etnográfico (re)visitado: o encontro etnográfico frente às experiências colaborativas. In: RAMOS, José Luis e MARTINEZ, Janeth (org.). Enseñar y aprender a investigar - experiencias varias en América. Cidade do México: EUMED.net - Biblioteca Virtual, 2018.

FREITAS, Ana Elisa de Castro e JACINTO DA ROSA, Douglas. Nas tramas de uma ecologia kaingang nanh ga: enlace, afeto e tradução. In: SANTOS, Boaventura de Sousa;

NUNES, João Arriscado e MENDES, José Manuel. Alice Metodologias. Coimbra: Centro de Estudos Sociais, no prelo.

GOMES, Cinara de Souza. As representações geométricas e zoomórficas da Tradição Planalto. A Arte nos Campos Gerais. Curitiba: Secretaria de Estado da Cultura, 2011.

INGOLD, Tim. Trazendo as coisas de volta a vida: emaranhados criativos num mundo de materiais. Horizontes Antropológicos. Porto Alegre, ano 18, n. 37, p. 25-44, jan./jun. 2012.

JACINTO DA ROSA, Douglas. Gestão socioambiental e territorial de terras indígenas sob uma perspectiva Kaingang: um ensaio (auto) etnográfico em Re Kuju - campo do meio, Bacia Hidrografica do Alto Uruguai, atual Estado do Rio Grande do Sul. Trabalho de Conclusão de Curso em Gestão Ambiental. Matinhos: UFPR, 2015.

KLEE, P. Notebooks, volume 1: the thinking eye. Ed. J. Spiller. London: Lund Humphries, 1961.

Noteboooks, volume 2: the nature of nature. Trans. H. Norden. Ed. J. Spiller. London: Lund Humphries, 1973.

NOELLI, Francisco Silva Noelli e SOUZA, Jonas Gregorio de. Novas perspectivas para a cartografia arqueológica Jê no Brasil meridional. Bol. Mus. Para. Emílio Goeldi. Cienc. Hum., Belém, v. 12, n. 1, p. 57-84, jan.-abr. 2017.

PIRES, Márcio de Oliveira. Cosmovisão Bakairi - Ekuro, nutrindo o Bem Viver. Anais da SIEPE. Curitiba: PROEC/UFPR, 2017.

SILVA, Nei da. O Corpo Kaingang na Escola: uma via metodológica de abordagem da Lei 11.645/2008 no ensino de Educação Física escolar. Trabalho de Conclusão de Curso em Educação Física. Curitiba: UFPR, 2017.

TOMMASINO, Kimiye. A história Kaingáng da bacia do Tibagi: uma sociedade Jê meridional em movimento. 1995. 351 f. Tese (Doutorado em Antropologia Social) Universidade de São Paulo, São Paulo, 1995.

VERGUEIRO, Davi; MELLO, Roseli Loureiro de e PIRES, Márcio de Oliveira. Impacto do cultivo da soja transgênica nas Terras Indígenas/ TIs da região Norte do Estado do Rio Grande do Sul, Brasil. In: FREITAS, Ana Elisa de Castro (org.). Intelectuais indígenas e a construção da universidade pluriétnica no Brasil. Série Trilhas do Conhecimento. LACED. Rio de Janeiro: E-papers, 2015, pp.237-249.

WARBURG, Aby. Histórias de fantasma para gente grande. São Paulo: Companhia das Letras, 2015. 